\title{
The possibility for surface-enhanced Raman scattering and spontaneous parametric down- conversion by globular photonic crystals infiltrated with dielectrics
}

\author{
Moiseyenko V.N., Dergachov M.P., Shvachich V.G. and Yevchik A.V. \\ Oles’ Honchar Dnipropetrovsk National University, 72 Gagarin Ave., 49010 \\ Dnipropetrovsk, Ukraine, e-mail: vnmois@yandex.ru
}

Received: 04.07.2009

\begin{abstract}
Emission of globular $\mathrm{SiO}_{2}$ photonic crystals infiltrated with dielectrics is observed within a wide spectral region under excitation with the light wavelength $\lambda=400 \mathrm{~nm}$. The first part of the emission spectrum located in the vicinity of the excitation line depends on infiltrated substance and is explained by surface-enhanced Raman scattering effect. The second one lying in the region of $440-650 \mathrm{~nm}$ that includes the stop-band is caused by spontaneous parametric down-conversion.
\end{abstract}

PACS: 78.67-n + 78.55.Mb

UDC: 535.361

Keywords: synthetic opal photonic crystals, photonic stop-band, density of vibrational states, spontaneous parametric down-conversion

\section{Introduction}

Optical phenomena in structures possessing spatial modulation of dielectric constant at distances close to the light wavelength (photonic crystals) are of a great interest because of the presence of forbidden gaps in their photonic band structure [1-3]. Synthetic opals made of $\mathrm{SiO}_{2}$ globules demonstrate pronounced stop-band for the light propagating along $<111>$ direction and modification of the photon density of states near the stop-band. Owing to possibility for changing their optical properties by infiltrating them with various substances, these materials have long been under extensive experimental study [4-6]. The emission of initial synthetic opal photonic crystals (SOPC) observed under ultraviolet excitation has been interpreted in terms of enhanced Raman and parametric scattering [7, 8]. At this time, similar opal emission under $400 \mathrm{~nm}$ dye laser excitation has been explained by the impurity luminescence [9].

The aim of the present work is to clear up the nature of emission peculiar for the initial and dielectrics-infiltrated synthetic opals, which occurs under excitation by photons of the energy higher than the high-frequency edge of the stop-band.

\section{Samples and experimental setup}

Dimensions of the SOPC samples in this study were about $1.0 \times 1.0 \times 0.1 \mathrm{~cm}^{3}$. Photonic stop-band positions were determined from the transmission spectra. The opal infiltration 
was made by soaking the initial samples into a water solution of dielectric materials, with a subsequent high-temperature annealing at the temperatures lower than the melting one $\left(595{ }^{\circ} \mathrm{C}\right.$ for $\mathrm{Ba}\left(\mathrm{NO}_{3}\right)_{2}, 630{ }^{\circ} \mathrm{C}$ for $\mathrm{CuCl}_{2}$ and $120{ }^{\circ} \mathrm{C}$ for $\left.\mathrm{LiIO}_{3}\right)$.

The emission of the SOPC was excited by LED Edixeon EDST-3LAx $\left(\lambda_{e x}=400 \mathrm{~nm}\right.$ and the average power of $30 \mathrm{~mW}$ ). The exciting radiation for all samples lied in the upper photonic band at a significant distance from the band edge. In some cases LED radiation located at $517 \mathrm{~nm}$ was employed for excitation. The emission spectra were measured in the forward and back scattering geometries with the use of modernised spectrometer DFS-12. They were detected within an aperture of $\leq 0.17 \pi \mathrm{sr}$ in the $\langle 111\rangle$ direction. Registration of a useful signal was carried out in a regime of photon counting with accumulation. Finally, spectral distribution in the emission spectra was corrected by subtracting the spectrum of exciting radiation.

\section{Results and interpretation}

As a result of $400 \mathrm{~nm}$ excitation, an intense emission band has been observed for all of our samples within the region of $400-440 \mathrm{~nm}$, i.e. near the exciting line. The spectral position of the band remains independent of the stop-band position in the initial samples (see curves 1 and 2 in Fig. 1a), though it is sensitive to the presence of infiltrated substance (Fig. 2a). It is known [9] that the luminescence of OH-groups in synthetic opals is detected in the region of 400-600 nm. In our case a broad band in the region of 510-650 nm was observed (curve 1 in Fig. 1a). This band disappears after hightemperature annealing of samples at $800{ }^{\circ} \mathrm{C}$ but the band in the vicinity of exciting line then becomes more intense (see curve 2 in Fig. 1a). In order to exclude the luminescence of OH-group defects, all the samples were annealed prior to the measurements.
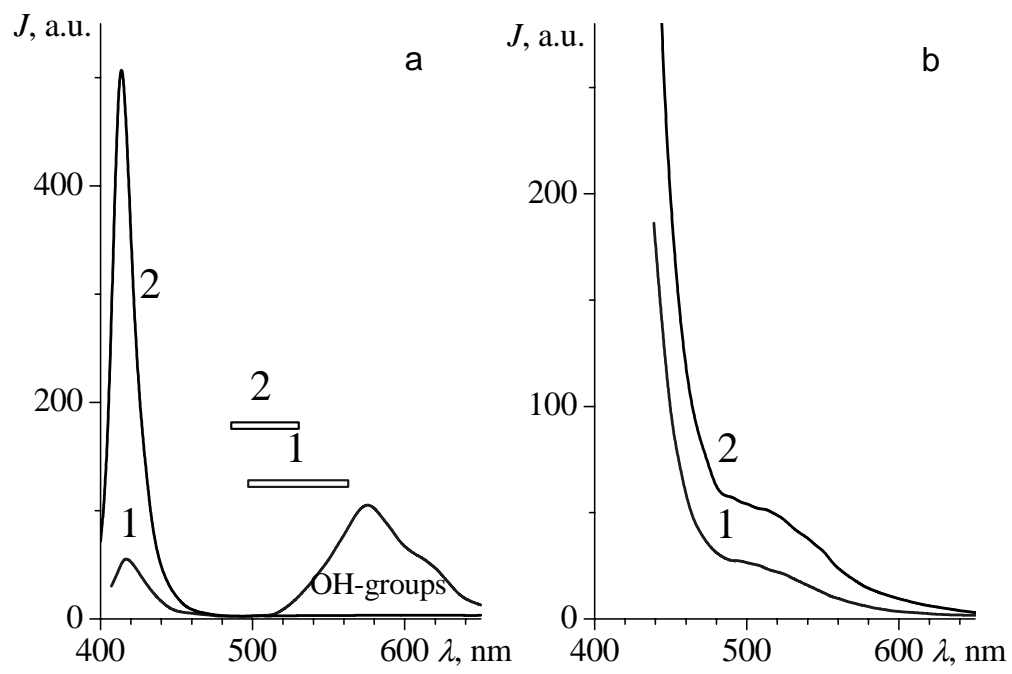

Fig. 1. (a) Emission spectra for the initial SOPC samples before (curve 1) and after (curve 2) annealing at $800{ }^{\circ} \mathrm{C}$, and (b) the same spectra for the samples infiltrated with $\mathrm{LilO}_{3}$ after two (curve 1) and three (curve 2) cycles of soaking into an aqueous $\mathrm{LilO}_{3}$ solution. The excitation is performed by irradiating at $\lambda_{e x}=400 \mathrm{~nm}$. Stop-band positions are marked with rectangles. 
Trying to understand the nature of the band located in the vicinity of the exciting line, we have used another excitation wavelength $(517 \mathrm{~nm})$. In this case the emission spectrum was also observed near the exciting line and was similar to that represented by curve 2 in Fig. 1a. These regularities allow us to suppose that the band observed near the exciting line is due to the surface-enhanced Raman scattering (SERS) by the substances forming the sample structure (in our case, $\mathrm{SiO}_{2}, \mathrm{CuCl}_{2}, \mathrm{Ba}\left(\mathrm{NO}_{3}\right)_{2}$ and $\mathrm{LiIO}_{3}$ ). It is known $[3,7]$ that there is a possibility for increasing optical field in the photonic crystal volume due to diffuse motion of photons with low velocity. This enables detecting such a process as the Raman scattering, even under weak excitation powers.

In order to obtain more detailed information on the spectral distribution of the SERS, we have measured, with the resolution of $2 \mathrm{~cm}^{-1}$, the emission spectra in the vicinity of the $400 \mathrm{~nm}$ exciting line under correct spectral conditions. These spectra are depicted in Fig. 2a on the standard Raman-shift scale. They are too wide, when compare with the usual Raman spectra. This could be explained by the two following reasons. The first one is a significant width of the exciting line $\left(\Delta \lambda_{e x} \approx 30 \mathrm{~nm}\right)$ and the second is a possible amorphous state of substances which form the sample structure. Then we can describe quantitatively the density of vibrational states $g(\Omega)$ for those substance by calculating the reduced Raman spectrum $J_{R}(\Omega)$ (for the Stokes component) as follows [10]:

$$
g(\Omega) \sim J_{R}(\Omega)=\Omega \cdot\left(\Omega_{L}-\Omega\right)^{-4} \cdot[n(\Omega, T)+1]^{-1} \cdot J(\Omega),
$$

where $\Omega$ denotes the Raman shift, $\Omega_{L}$ the incident photon frequency $\left(4.71 \cdot 10^{15} \mathrm{~s}^{-1}\right)$, $n(\Omega, T)$ the Bose-Einstein factor and $J(\Omega)$ the Raman spectrum measured. The reduced Raman spectra calculated after neglecting $\Omega$ in the multiplier $\left(\Omega_{L}-\Omega\right)^{-4}$ are presented in Fig. 2b.

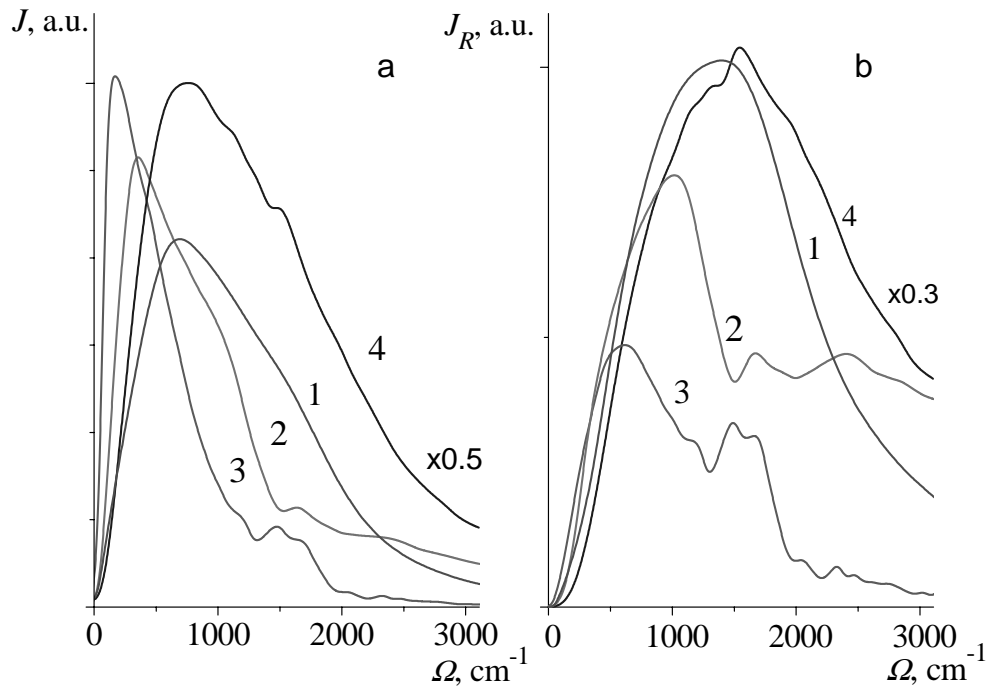

Fig. 2. (a) Emission spectra in the vicinity of the $400 \mathrm{~nm}$ exciting line and (b) the corresponding reduced Raman spectra for the initial SOPC sample (curves 1) and the samples infiltrated with $\mathrm{CuCl}_{2}$ (curve 2), $\mathrm{Ba}\left(\mathrm{NO}_{3}\right)_{2}$ (curve 3) and $\mathrm{LilO}_{3}$ (curve 4). 
Besides the intense band located near the exciting line, a wide continuum is observed within the 460-640 $\mathrm{nm}$ region in the spectrum peculiar for the $\mathrm{LiIO}_{3}$-infiltrated sample (see curves 1 and 2 in Fig. 1b). The latter is also observed in the spectrum for another sample infiltrated with $\mathrm{Ba}\left(\mathrm{NO}_{3}\right)_{2}$. The spatial distribution of emission intensity for the sample with $\mathrm{Ba}\left(\mathrm{NO}_{3}\right)_{2}$ is shown in Fig. 3a. The spectral distributions of emission intensity for the both samples (after subtracting the intense band located near the $400 \mathrm{~nm}$ line) are similar (see Fig. 3b). To fill the pores of the synthetic opals, several infiltration cycles have been made, keeping the temperature of aqueous $\mathrm{LiIO}_{3}$ solution to be $60{ }^{\circ} \mathrm{C}$. The emission intensity within the $460-640 \mathrm{~nm}$ region has proportionally increased with increasing quantity of infiltration cycles (see Fig. 1b). Moreover, as seen from Fig. 3b, there is a good correlation between the position of the intensity maximum and the stopband position. These facts allow us to assume some other nature of this emission band rather than the impurity luminescence.

Namely, the origin of this continuum may be explained by spontaneous parametric down-conversion (SPDC) occurring in spatially non-uniform samples with a regular structure. The SPDC can be most probably observed in the vicinity of maxima of the photon density of states at the edges of the stop-band, if we deal with synthetic opals infiltrated with substances possessing relatively high $\chi^{(2)}$ values. The SPDC spectral distribution observed represents a sum of spectral bands for each of single pores containing nonlinear substance. These bands are shifted with regard to the corresponding band position in a uniform medium, in accordance with a "quasi-phase matching" condition. In addition to this, an interference of radiation from different pores should take place [11]. The SOPC emission appears inside the stop-band due to existence of some own optical states caused by defects and structural disordering of samples.

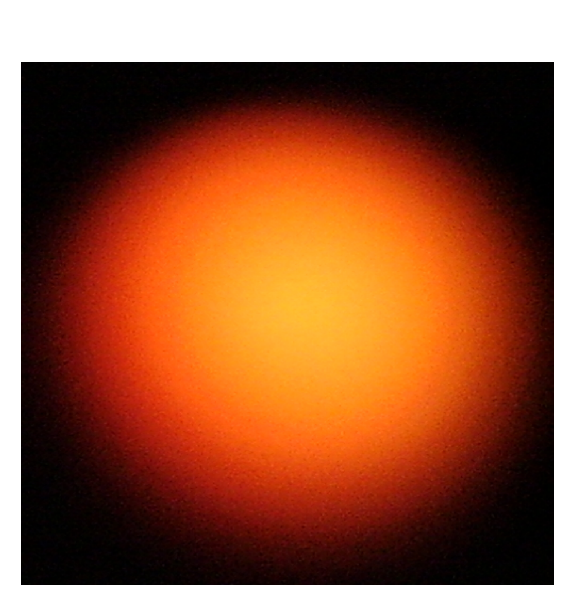

a

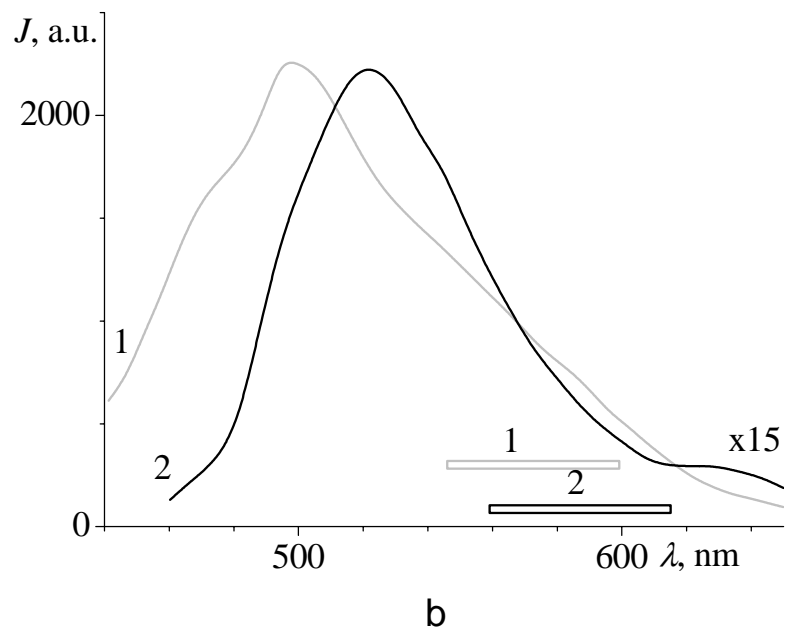

Fig. 3. (a) Photo of SPDC emission for the SOPC infiltrated with $\mathrm{Ba}\left(\mathrm{NO}_{3}\right)_{2}$, and (b) its SPDC spectrum (curve 1) and spectrum for the SOPC infiltrated with $\mathrm{LilO}_{3}$ (curve 2) under excitation at $\lambda_{e x}=400 \mathrm{~nm}$. Stop-band positions are marked with rectangles. 


\section{Conclusion}

Emission of the initial and dielectrics-infiltrated synthetic opals is observed under the excitation at $\lambda=400 \mathrm{~nm}$. Interpretation of the secondary emission spectra of initial opals is made in terms of SERS that reflects the density of vibrational states. The emission of $\mathrm{Ba}\left(\mathrm{NO}_{3}\right)_{2}$ - and $\mathrm{LiIO}_{3}$-infiltrated opal appearing as a wide structural continuum is due to the SPDC, i.e. three-photon parametric light scattering.

\section{References}

1. Bykov V P, 1972. Spontaneous emission in a periodic structure. Sov. Phys. JETP. 35: 269-273.

2. Yablonovitch E, 1987. Inhibited spontaneous emission in solid-state physics and electronics. Phys. Rev. Lett. 58: 2059-2062.

3. John S, 1987. Strong localization of photons in certain disordered dielectric superlattices. Phys. Rev. Lett. 58: 2486-2489.

4. Romanov S G and Fokin A V, 2003. Change of spontaneous emission in stop-band of opal with magnified contrast of refraction index. Fiz. Tverd. Tela. 45: 419-423.

5. Bechger L, Lodahl P and Vos W L, 2005. Directional fluorescence spectra of laser dye in opal and inverse opal photonic crystals. J. Phys. Chem. B. 109: 9980-9988.

6. Emelchenko G A, Gruzincev A N, Kovalchuk M N, Maslov V M, Samarov E N, Yakimov E E, Barthou C and Zverkova I I, 2005. Opal-ZnO nanocomposites: structure and emission properties. Fiz. Tekhn. Poluprov. 39: 1375-1379.

7. Gorelik V S, 2007. Optics of globular photonic crystals. Kvant. Elektron. 37: 409432.

8. Moiseyenko V N, Guziy O O, Gorelik V S and Dergachov M P, 2008. Optical excited secondary emission spectra of photonic crystals based on synthetic opals. Opt. Spectroscopy. 105: 919-923.

9. Emelchenko G A, Maslov V M, Romanelli M, Maitre A, Barthou C, Benalloul P, Gruzincev A N and Yakimov E E, 2007. Angle-resolved self-activated luminescence of 3D photonic crystals - opals. Proc. Metamaterials'2007: 346-349.

10. Light scattering in solids, Ed. by M. Cardona, Springer-Verlag, Berlin (1975).

11. Kitayeva G Kh and Penin A N, 2005. Spontaneous parametric light scattering. JETP Lett. 82: 388-394.

Moiseyenko V.N., Dergachov M.P., Shvachich V.G. and Yevchik A.V., 2009. The possibility for surface-enhanced Raman scattering and spontaneous parametric down-conversion by globular photonic crystals infiltrated with dielectrics Ukr.J.Phys.Opt. 10: 201-205.

Анотація. Випромінювання глобулярних $\mathrm{SiO}_{2}$ фотонних кристалів з інфільтрованими діелектриками спостерігалось в широкому спектральному діапазоні при збудженні світлом з довжиною хвилі випромінювання $\lambda=400$ нм. Перша частина спектру випромінювання локалізована поблизу лінії збудження залежить від інфільтрованої речовини і пояснюється поверхнево-підсиленим комбінаційним розсіянням. Друга частина, яка знаходиться в області 440-650нм, що включає стоп-зону, спричинена спонтанним параметричним розсіянням.

Ukr. J. Phys. Opt. 2009, V10, №4 